\title{
Effects of acute versus post-acute systemic delivery of neural progenitor cells on neurological recovery and brain remodeling after focal cerebral ischemia in mice
}

\author{
TR Doeppner,,1, B Kaltwasser ${ }^{1}$, MK Teli ${ }^{1,2}$, E Bretschneider ${ }^{3,4}$, M Bähr ${ }^{4}$ and DM Hermann ${ }^{1}$
}

Intravenous transplantation of neural progenitor cells (NPCs) induces functional recovery after stroke, albeit grafted cells are not integrated into residing neural networks. However, a systematic analysis of intravenous NPC delivery at acute and post-acute time points and their long-term consequences does not exist. Male C57BL6 mice were exposed to cerebral ischemia, and NPCs were intravenously grafted on day 0 , on day 1 or on day 28 . Animals were allowed to survive for up to 84 days. Mice and tissues were used for immunohistochemical analysis, flow cytometry, ELISA and behavioral tests. Density of grafted NPCs within the ischemic hemisphere was increased when cells were transplanted on day 28 as compared with transplantation on days 0 or 1 . Likewise, transplantation on day 28 yielded enhanced neuronal differentiation rates of grafted cells. Post-ischemic brain injury, however, was only reduced when NPCs were grafted at acute time points. On the contrary, reduced post-ischemic functional deficits due to NPC delivery were independent of transplantation paradigms. NPC-induced neuroprotection after acute cell delivery was due to stabilization of the blood-brain barrier (BBB), reduction in microglial activation and modulation of both peripheral and central immune responses. On the other hand, post-acute NPC transplantation stimulated post-ischemic regeneration via enhanced angioneurogenesis and increased axonal plasticity. Acute NPC delivery yields long-term neuroprotection via enhanced BBB integrity and modulation of post-ischemic immune responses, whereas post-acute NPC delivery increases post-ischemic angioneurogenesis and axonal plasticity. Post-ischemic functional recovery, however, is independent of NPC delivery timing, which offers a broad therapeutic time window for stroke treatment.

Cell Death and Disease (2014) 5, e1386; doi:10.1038/cddis.2014.359; published online 21 August 2014

Evidence from experimental stroke trials suggests that transplanted stem cells or progenitor cells improve neurological deficits following ischemic stroke. In this context, cells from various species and different tissue sources have been shown to induce both histological and functional recovery after cerebral ischemia, albeit grafted cells are generally not thought to be integrated into the residing neural network. ${ }^{1-7}$ Although multipotent stem cells like embryonic stem cells might be attractive tools for neuroregenerative approaches, both tumor formation rates and ethical concerns limit their application. ${ }^{8,9}$ Consequently, transplantation of adult stem cells or progenitor cells such as neural progenitor cells (NPCs) might overcome these limitations. ${ }^{10}$

NPCs can be obtained from different tissues such as the subventricular zone (SVZ) of the lateral ventricles and the subgranular zone of the dentate gyrus. ${ }^{3}$ After in vitro expansion, they induce promising therapeutic outcomes without serious side effects. ${ }^{2,11-15}$ Although the most 'ideal' delivery route of both stem cells and NPCs remains to be determined, there is evidence affirming the feasibility of intravenous administration of stem cells. ${ }^{13,16-19}$ As such, intravenous NPC delivery is not inferior to intracranial cell transplantation routes, despite low intracerebral numbers of grafted cells detectable, ${ }^{4}$ making it thus attractive for clinical applications.

In spite of promising studies on the potential of NPCs as a versatile tool in stroke treatment, fundamental questions are yet to be answered. For instance, no study exists that systematically analyses how different time points of intravenous NPC delivery influence stroke recovery and brain plasticity in the long run. While early NPC transplantation may gain advantage of chemotactic pro-inflammatory signals, a hostile environment may also impair the long-term survival of grafted cells. Conversely, post-acute delivery of cells may prevent secondary neurodegeneration and enhance the selfrecovery of the brain. ${ }^{3}$ However, the majority of intravenous transplantation studies have used a therapeutic time window of $24-48 \mathrm{~h}$ post stroke, followed by observation periods of usually 2-4 weeks. ${ }^{17}$ Bacigaluppi et al. ${ }^{11}$ have extended this

\footnotetext{
${ }^{1}$ Department of Neurology, University of Duisburg-Essen Medical School, Essen, Germany; ${ }^{2}$ National Institute of Technology Calicut, Calicut, Kerala, India; ${ }^{3}$ Department of Otorhinolaryngology, Johannes Wesling Klinikum, Minden, Germany and ${ }^{4}$ Department of Neurology, University of Goettingen Medical School, Goettingen, Germany ${ }^{*}$ Corresponding author: TR Doeppner, Department of Neurology, University of Duisburg-Essen Medical School, Hufelandstrasse 55, Essen 45147, Germany. Tel: +49 201723 83586; Fax: +49 201723 1660; E-mail: thorsten.doeppner@uk-essen.de

Abbreviations: BBB, blood-brain barrier; BDA, biotinylated dextrane amine; BDNF, brain-derived neurotrophic factor; bFGF, basic fibroblast growth factor; BrdU, bromodeoxyuridine; CD, cluster of differentiation; CNPase, 2,3-cyclic nucleotide phosphodiesterase; DAB, 3,3'-diaminobenzidine; DAPI, 4',6-diamidino-2-phenylindole; EDTA, ethylenediaminetetraacetic acid; EGF, epidermal growth factor; ELISA, enzyme linked immunosorbent assay; GDNF, glial cell-derived neurotrophic factor; GFAP, glial fibrillary acidic protein; GFP, green fluorescent protein; MCAO, middle cerebral artery occlusion; NGF, nerve growth factor; NPCs, neural progenitor cells; PBS, phosphate-buffered saline; ROIs, regions of interest; RT, room temperature; SVZ, subventricular zone; TTC, triphenyl tetrazolium chloride; TUNEL, TdT-mediated dUTP-biotin nick end labeling; VEGF, vascular endothelial growth factor

Received 18.6.14; revised 19.7.14; accepted 21.7.14; Edited by A Verkhratsky
} 
time window up to $72 \mathrm{~h}$. To our knowledge, no data are available related to delayed single intravenous delivery of native cultivated NPCs beyond this time point.

In the present study, we have thus investigated the outcome of intravenous administration of adult SVZ-derived NPCs at acute and post-acute time points after induction of transient focal cerebral ischemia in mice, followed by an observation period of 3 months post stroke. Our data provide a temporal and systematic comparison of intravenous NPC therapy in stroke on both histological and behavioral parameters, which might set the path for future clinical trials and therapeutic approaches in the field.

\section{Results}

Transplantation of NPCs during early reperfusion induces acute neuroprotection. Before analyzing adequate cell delivery time points, determination of appropriate NPC numbers to induce acute neuroprotection was established. Mice therefore received intravenous injections of $10^{6}$, $5 \times 10^{6}$ or $10^{7}$ NPCs during the beginning of post-ischemic reperfusion. Control mice received phosphate-buffered saline (PBS) only. Analysis of infarct volumes using cresyl violet staining on day 2 revealed significantly reduced brain injury in all animals that had been treated with NPCs as compared with control mice (Figures $1 \mathrm{a}$ and $\mathrm{b}$ ).

Densities of NPCs detected within the ischemic hemisphere were significantly increased in mice that had been given $10^{7}$ cells as compared with mice receiving $10^{6}$ cells only (Figure 1c). However, cells were typically scattered within the lesion site (Figure 1d) with the overall amount of grafted cells being relatively low under each experimental condition. Noteworthy, injection of high cell numbers (i.e., $10^{7}$ NPCs) did not further reduce brain injury in these animals (Figures 1a and $b$ ). As a matter of fact, some animals died when injected with $10^{7}$ NPCs in a given volume of PBS. In the present study, further experiments were therefore performed using intravenous injections of $10^{6}$ NPCs only.

Increased intracerebral density of grafted NPCs after post-acute cell transplantation. Analysis of grafted NPC numbers on days 56 and 84 within the ischemic hemisphere revealed significantly increased cell numbers when NPCs were transplanted on day 28 as compared with transplantation of NPCs on days 0 or 1 (Figure 2a). On the contrary, density of NPCs that had been grafted on days 0 or 1 did not differ between each other at the aforementioned time points. There was also no significant difference in cell numbers on day 28 within the ischemic hemisphere of mice that had been injected with NPCs on day $0\left(48.8 \pm 8.2 \mathrm{NPCs} / \mathrm{mm}^{2}\right)$ or on day $1\left(44.3 \pm 5.7 \mathrm{NPCs} / \mathrm{mm}^{2}\right)$ after induction of stroke. Analysis of grafted NPCs in the contralateral non-ischemic hemisphere yielded no significant difference between the various experimental paradigms, albeit cell numbers were always significantly lower as compared with the corresponding ipsilateral ischemic hemisphere (data not shown).

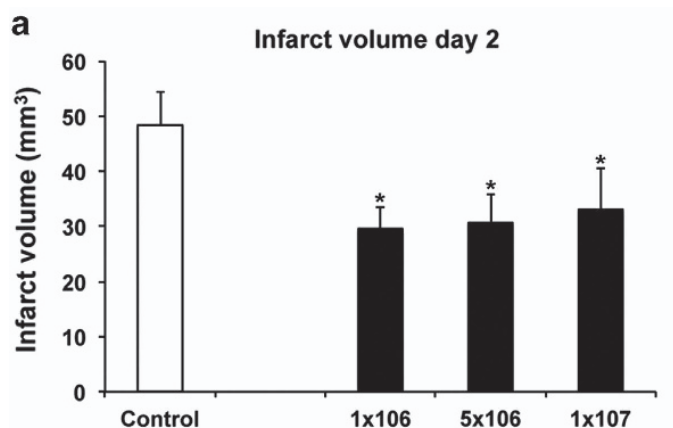

C

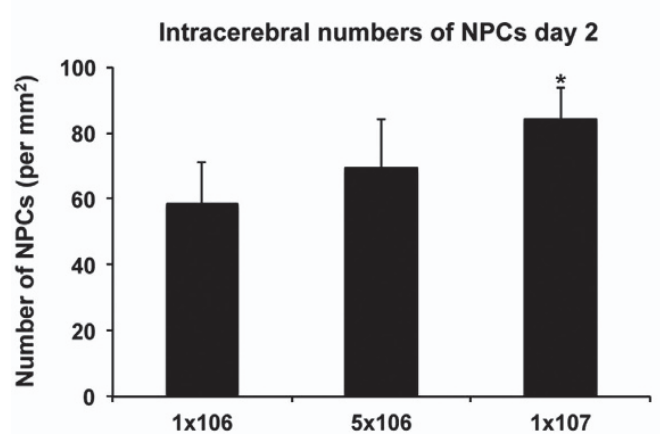

b

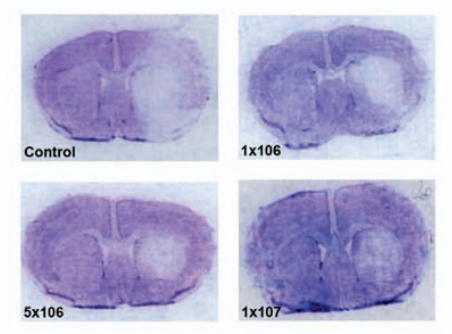

d
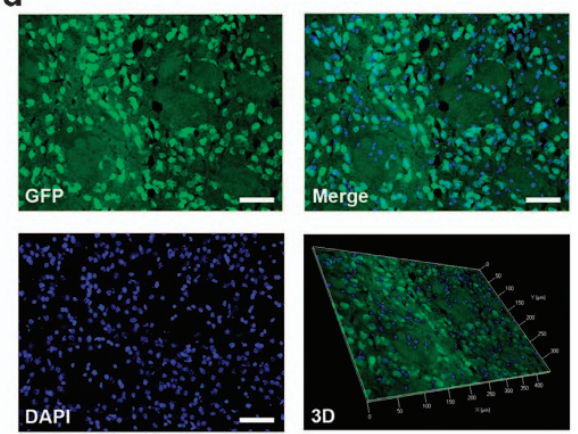

Figure 1 Acute transplantation of neural progenitor cells (NPCs) is neuroprotective. NPCs or PBS (control) was intravenously administered during reperfusion after induction of stroke. (a) Different numbers of NPCs were transplanted intravenously (solved in $200 \mu$ l of PBS) and infarct volumes were assessed on day 2 post stroke using cresyl violet staining. (b) Representative photographs for each condition shown in (a). (c) Analysis of grafted GFP ${ }^{+}$NPCs within the ischemic hemisphere 2 days after stroke. (d) Representative photographs of GFP ${ }^{+}$NPCs within the ischemic lesion site as exemplarily taken from mice that received $10^{7}$ NPCs. All data are given as mean \pm S.D. *Significantly different from the corresponding control, $P<0.05$. Scale bars: $50 \mu \mathrm{m}$ 


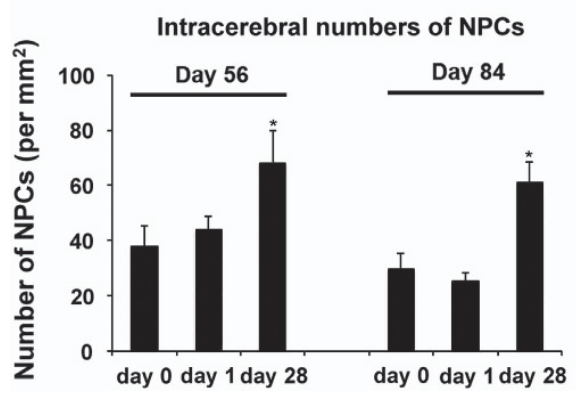

b

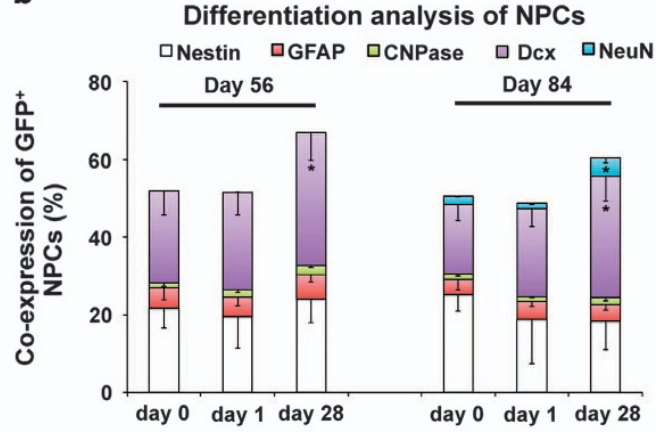

Figure 2 Post-acute transplantation of neural progenitor cells (NPCs) yields high neuronal differentiation rates. NPCs were intravenously transplanted at the time points given (i.e., day 0 , day 1 , and day 28 post stroke) and animals were killed on day 56 or on day 84 followed by immunohistochemical analyses. (a) Assessment of GFP ${ }^{+}$NPCs within the ischemic hemisphere depending on cell delivery time points. (b) Differentiation analysis of GFP ${ }^{+}$NPCs from (a) regarding co-expression of Nestin, GFAP, CNPase, Dcx and NeuN. All data are given as mean \pm S.D. *Significantly different from controls, $P<0.05$

Differentiation analysis revealed co-expression of grafted NPCs with the neural marker nestin, the astroglial marker GFAP, the oligodendroglial marker CNPase, the immature neuronal marker doublecortin (Dcx) and the mature neuronal marker NeuN (Supplementary Figure S1). Co-expression of $\mathrm{GFP}^{+}$transplanted NPCs (Figure $2 \mathrm{~b}$ ) with neuronal markers was significantly increased on days 56 and 84 when cells were transplanted on day 28 post stroke. Mature neuronal differentiation as observed by NeuN co-expression, however, was only observed on day 84 after induction of stroke.

Acute NPC transplantation reduces post-ischemic brain injury. To assess post-ischemic brain injury, neuronal densities were analyzed on day 56 (Figure 3a) and on day 84 (Figure $3 b$ ) post stroke, as described in the Materials and Methods. Transplantation of NPCs on day 0 or on day 1 yielded significant neuroprotection for as long as 84 days after induction of stroke when compared with PBS controls. Interestingly, transplantation of NPCs on day 28 post stroke did not induce neuroprotection as assessed by neuronal density, neither on day 56 nor on day 84 .

NPCs induce post-ischemic functional recovery independent of transplantation timing. Since reduced brain injury as assessed by histological analysis does not necessarily reflect reduced functional impairment, behavioral tests were performed at the time points given for each experimental condition. Using the rota rod, the tight rope and the corner turn test, animals that had received systemic injection of NPCs on day 0 or on day 1 showed better functional outcome than controls (Figures $4 a-c)$. Noteworthy, mice that had received NPC transplantation on day 28 post stroke also significantly performed better in the behavioral tests (Figures $4 \mathrm{a}-\mathrm{c}$ ), albeit brain injury was not affected under this experimental paradigm (Figure 3). Better test scores of the latter were, however, not immediately evident at the beginning of the behavioral tests.

Behavioral results in the water maze test were in line with the aforementioned motor coordination tests. Mice that were given NPCs on days 0 or 1 always showed better test performance in the water maze test than control mice. Likewise, transplantation of NPCs on day 28 induced improved functional outcome in the water maze test as observed at later time points of the experimental paradigm. These data suggest that transplantation of NPCs on day 28 is likely to enhance neural regeneration rather than initial neuroprotection, as is the case with acute cell delivery time points on day 0 or on day 1 .

Acute transplantation of NPCs induces neuroprotection via stabilization of blood-brain barrier and reduction in post-ischemic cerebral inflammation. Transplantation of NPCs on day 0 or on day 1 reduced infarct volumes as assessed by TTC staining on day 2 post stroke (Figure 5a). In line with this, analysis of $\mathrm{TUNEL}^{+}$cells revealed significantly reduced numbers of $\mathrm{TUNEL}^{+}$cells in mice that had been treated with NPCs when compared with control animals (Figure 5b). Acute neuroprotection due to transplantation of NPCs was associated with increased stability of the blood-brain barrier (BBB), as suggested by Evans blue extravasation (Figure $5 \mathrm{c}$ ). Furthermore, numbers of activated microglia within the ischemic hemisphere were significantly decreased after treatment with NPCs, regardless of transplantation timing (Figure 5d).

Acute NPC delivery modulates peripheral and central immune response. Since stem cells like hematopoietic stem cells as well as mesenchymal stem cells (MSCs) are known to modulate immune responses, $, 20,21$ we further analyzed both peripheral and central leukocyte responses on day 2 post stroke. Induction of cerebral ischemia itself significantly increased both peripheral and central numbers of leukocytes in all experimental groups when compared with non-ischemic mice (data not shown). However, both peripheral and central absolute numbers of leukocytes were significantly reduced on day 2 post stroke when mice had received intravenous injections of NPCs (Figure 6). No difference was observed between the two treatment paradigms, that is, injection of NPCs on day 0 or on day 1 (Figure 6). These data suggest that early transplantation of NPCs induces post-ischemic modulation of both peripheral and central immune responses, albeit the latter might be a consequence of changed peripheral immune state and stabilization of the BBB due to NPC transplantation (Figure 5). 
a

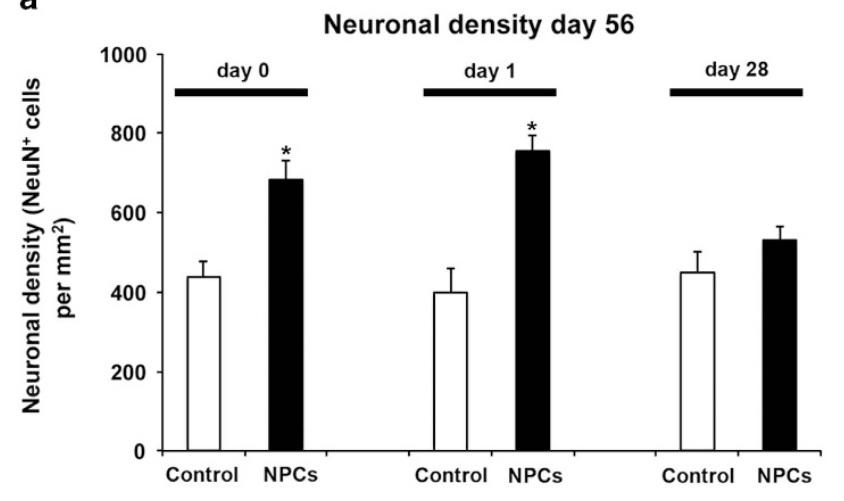

b

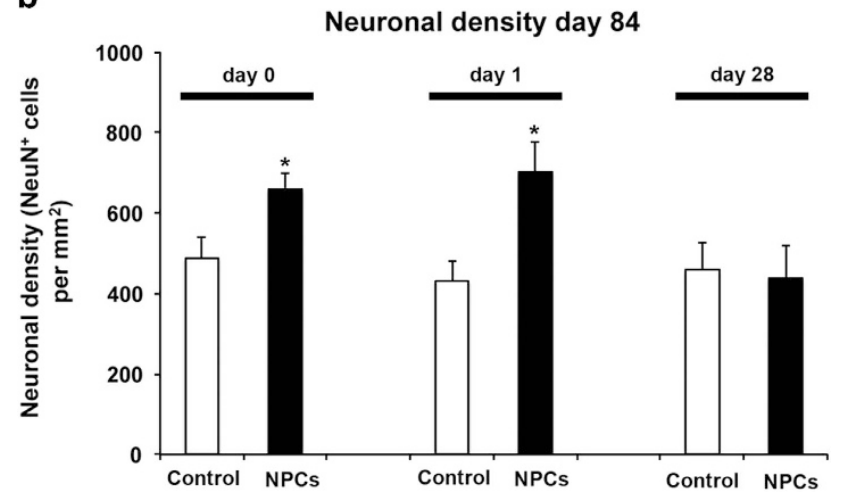

Figure 3 Sustained reduction of post-ischemic brain injury requires acute cell transplantation. Neural progenitor cells (NPCs) were grafted at the time points given, whereas control animals received PBS only. Post-stroke brain injury was assessed via analysis of neuronal density both on day 56 (a) and on day 84 (b). All data are given as mean \pm S.D. ${ }^{*}$ Significantly different from controls, $P<0.05$

Analyzing further mechanisms in this respect was, however, beyond the scope of the present work that focuses on NPC delivery time points and not on mechanisms of inflammatory responses after stroke.

Post-acute NPC transplantation is associated with increased post-ischemic angioneurogenesis and stimulation of neuroplasticity. Transplantation of NPCs supports post-ischemic endogenous neurogenesis., 4,22 As such, we wondered whether timing of cell delivery affects both angioneurogenesis and neuroplasticity in the long run after induction of cerebral ischemia. Analysis of $\mathrm{BrdU}^{+}$cells on day 84 post stroke revealed no significant difference to controls when NPCs were transplanted on day 0 or on day 1 . On the contrary, the amount of $\mathrm{BrdU}^{+}$cells within the ischemic hemisphere was significantly increased when cells were transplanted on day 28 post stroke (Figure 7a). Differentiation analysis of endogenous newborn $\mathrm{BrdU}^{+}$cells showed enhanced neuronal differentiation rates after transplantation of NPCs on day 28 post stroke when compared with controls (Figure 7b). Again, no significant difference was observed when NPCs were grafted on day 0 or on day 1.

As neurogenesis and angiogenesis affect each other mutually, we next analyzed post-ischemic vessel density in the ischemic striatum on day 84 after induction of stroke. We found an increased number of $\mathrm{CD}_{3}{ }^{+}$cells in mice that had been treated with NPCs on day 28, but not on day 0 or on day 1 (Figure 7c). Subsequent analysis of cells expressing both BrdU and CD31 as a means for assessment of post-ischemic angiogenesis revealed significantly increased co-labeling in mice that had been given NPCs on day 28. In detail, we found the following percentage of $\mathrm{BrdU}^{+}$cells expressing CD31 on day 84 post stroke: $5.8 \pm 0.9 \%$ in control versus $6.8 \pm 1.1 \%$ in NPC animals (transplantation on day 0 ), $6.3 \pm 0.4 \%$ in control versus $7.4 \pm 1.9 \%$ in NPC animals (transplantation on day 1 ) and $6.7 \pm 1.3 \%$ in control animals versus $13.8 \pm 2.9 \%$ in NPC animals (transplantation on day 28 ).

Since post-ischemic neuroregeneration does not only imply neuroregeneration in terms of neuronal differentiation of newborn cells but also axonal plasticity and density of projecting axons, we then analyzed axonal density in the ischemic hemisphere on day 84 post stroke. Using anterograde tract tracer injection into the contralateral motor cortex as described in the Materials and Methods and by Yan et al., ${ }^{23}$ ipsilateral cerebral axonal density was significantly increased in mice that had been given NPCs on day 28 when compared with controls (Figure 7d). However, no significant difference was observed when NPCs were grafted on day 0 or on day 1 post stroke (Figure 7d).

Although transplanted NPCs might not be integrated into the residing neural network within the ischemic brain, the latter can be modified by release of cellular mediators from grafted cells. ${ }^{4}$ As such, we measured the concentration of various growth factors within the ischemic hemisphere on day 84 after induction of stroke (Table 1). Using ELISA tests, analysis revealed increased levels of BDNF, GDNF and VEGF within brains of mice that had been treated with NPCs on day 28 after stroke. No significant difference between the various experimental groups was observed when treatment started on day 0 or day 1 , suggesting that only transplantation of NPCs at postacute stages of the disease modulates the post-ischemic cellular milieu.

\section{Discussion}

The present study analyzed effects of cell delivery timing for intravenous transplantation of NPCs and their underlying mechanisms after cerebral ischemia in mice. Although only acute cell delivery reduces histological brain injury, functional impairment is reduced after transplantation of NPCs at both acute and chronic stages of the disease. Whereas the former mediates neuroprotection via stabilization of the BBB and modulation of both peripheral and central immune responses, the latter stimulates post-ischemic neuroregeneration and changes the extracellular milieu.

Studies using intravenous transplantation of NPCs as a means to treat experimental stroke typically apply cell numbers in the order of one million cells. ${ }^{14}$ However, adequate cell dosages for transplantation remain elusive. Consequently, we first studied effects of grafted cell numbers on acute neuroprotection when cells were given during reperfusion. Although the amount of intracerebral cells detected gradually inclined with increased numbers of grafted cells, neuroprotection was independent of transplanted NPC numbers under these conditions. This is in line with previous studies from our group, ${ }^{4}$ where systemic transplantation of 
a
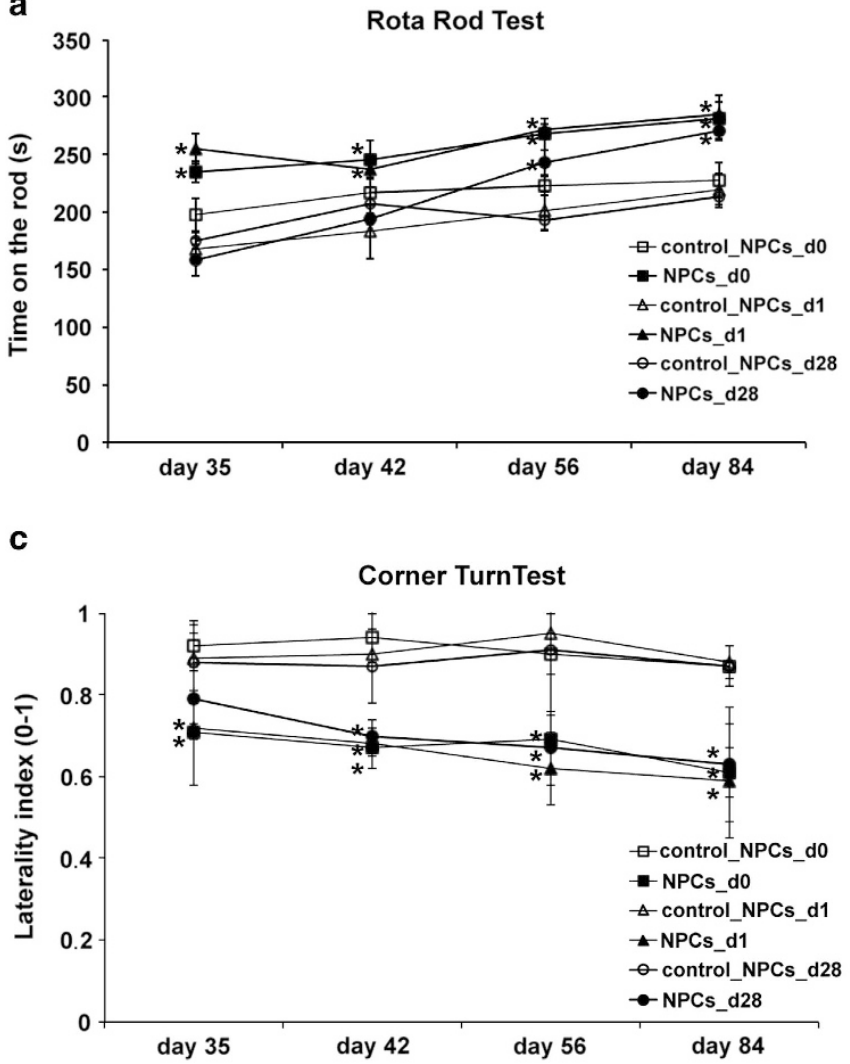

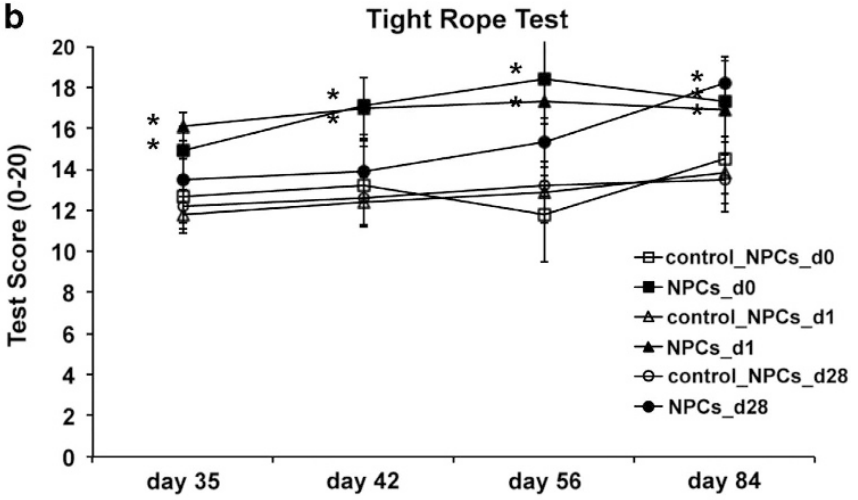

d

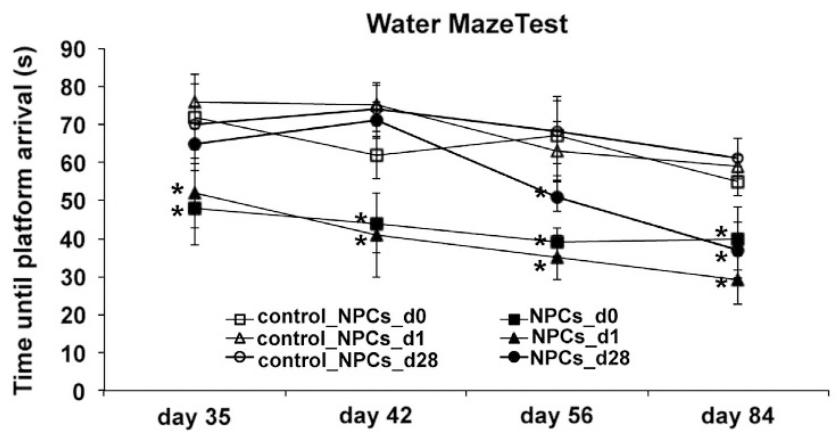

Figure 4 Improved post-ischemic functional recovery is independent of cell delivery timing. Assessment of post-stroke functional recovery was analyzed on days 35,42 , 56 and 84 using the rota rod (a), the tight rope (b), the corner turn (c) and the water maze test (d). Neural progenitor cells (NPCs) were intravenously transplanted at the time points given, whereas controls received PBS only. Maximal testing time was $300 \mathrm{~s}$ for the rota rod test (a). The tight rope test (b) was analyzed using a validated score from 0 ( $\mathrm{min}$ ) to 20 (max). For the corner turn test (c), the laterality index was calculated using the following formula: (number of left turns - number of right turns)/10. Water maze test performance (d) was analyzed at the time points given. Mice were tested for maximal $90 \mathrm{~s}$ per run. Data are given as means out of eight runs. If animals did not reach the platform, then they were scored $90 \mathrm{~s}$. Behavioral data from all tests are given as mean \pm S.D. *Significantly different from controls, $P<0.05$

NPCs induced long-term neuroprotection despite low intracerebral cell numbers. On the contrary, stereotactic intracerebral transplantation requires sufficiently high amounts of cells for modulation of the post-ischemic cellular milieu, ${ }^{4}$ where therapeutic effects are dose dependent as described by Stroemer et al. ${ }^{24}$

Systemic transplantation of stem cells such as MSCs has been shown in rodents for time points until 1 month after stroke ${ }^{25}$ albeit the majority of studies focused on acute or subacute cell delivery time points only. Whereas intraarterial transplantation of NPCs has been shown for as late as 14 days post stroke, ${ }^{26}$ clinically more relevant intravenous transplantation of NPCs is limited to acute and subacute time points only. To our knowledge, no study exists on single intravenous transplantation of native NPCs beyond $72 \mathrm{~h}$ after stroke that also includes a systematic analysis of mechanisms involved. Using double intravenous administration of NPCs, Song et al. $^{27}$ extended the aforementioned time window by transplanting cells on day 7 , but failed to show an additional therapeutic benefit contributed to the second transplantation of NPCs. In this context, Moriyama et al. ${ }^{28}$ intravenously grafted NPCs on day 7 in a model of post-ischemic depression, showing that NPCs improved stroke-induced depression without affecting histological brain injury. On the contrary, stereotactic intracerebral cell delivery is likely to offer a broader therapeutic time window, although clinical implications are limited due to invasive surgical procedures. In this context, NPCs were stereotactically applied in various stroke models for as late as 6 weeks post stroke, ${ }^{12,29}$ not necessarily resulting in better outcome than early intracerebral cell engraftment.

Post-stroke transplantation of stem cells or progenitor cells does not result in integration of grafted cells. Rather, grafted cells like NPCs are thought to modify the post-ischemic cellular milieu via indirect effects. .,3,11,30 $^{2}$ Accordingly, relevant neuronal differentiation rates or even integration of grafted cells was not observed in the present study-or is unlikely at the least. As such, increased expression of immature and mature neuronal markers in NPCs that had been transplanted 4 weeks after stroke is a consequence of enhanced survival of grafted cells. The latter were transplanted at a time point when maximal inflammatory responses had already diminished, ${ }^{31}$ thus resulting in a less hostile extracellular environment.

In the present study, brain injury as assessed by infarct volume and neuronal density was reduced after acute cell delivery only. This is in line with previous observations, suggesting that acute cell delivery is in order when brain injury 
a

\section{Infarct volume day 2}

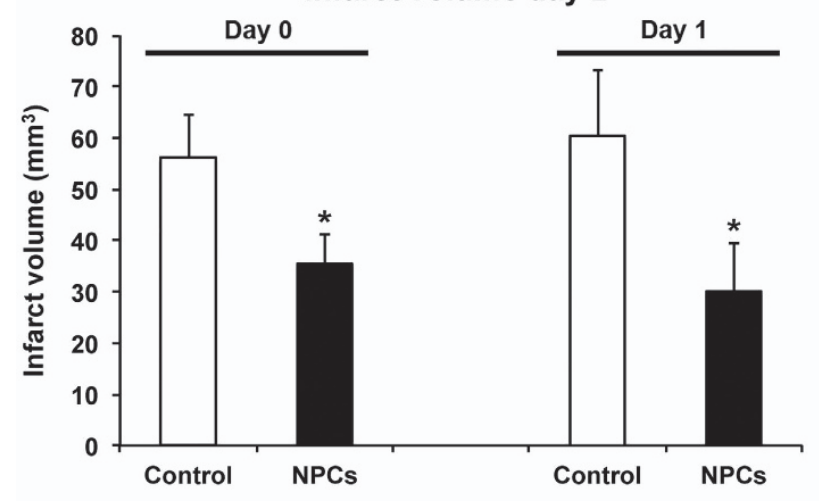

Day 0

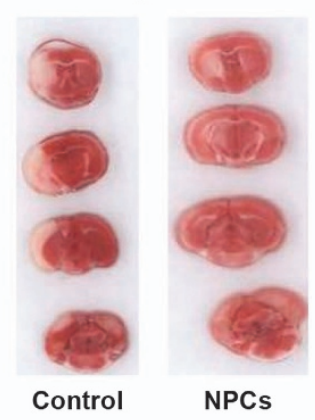

Transplantation Day 0
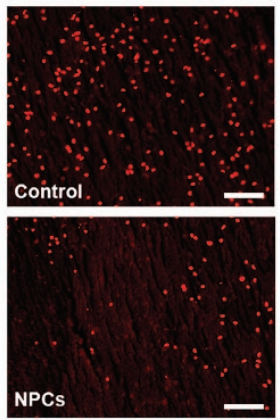

Day 1

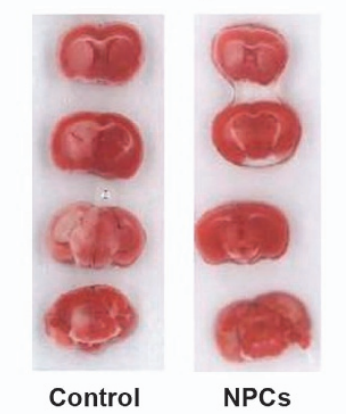

\section{。}

TUNEL ${ }^{+}$cells day 2

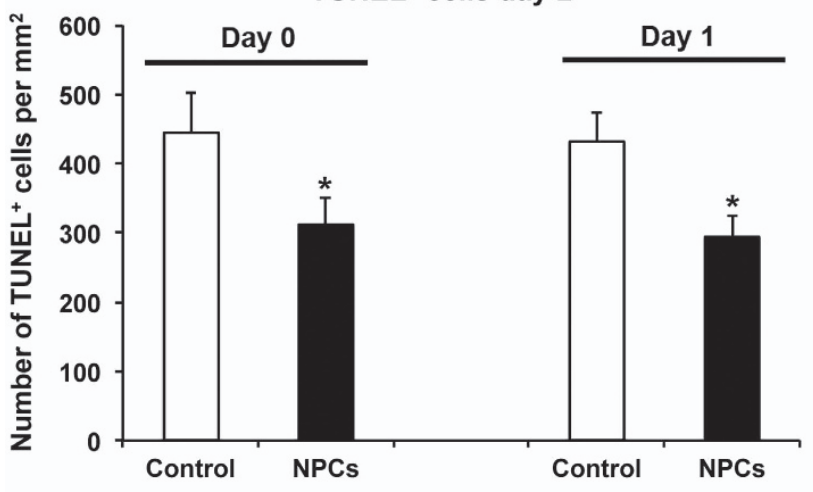

C Blood-brain-barrier integrity day 2

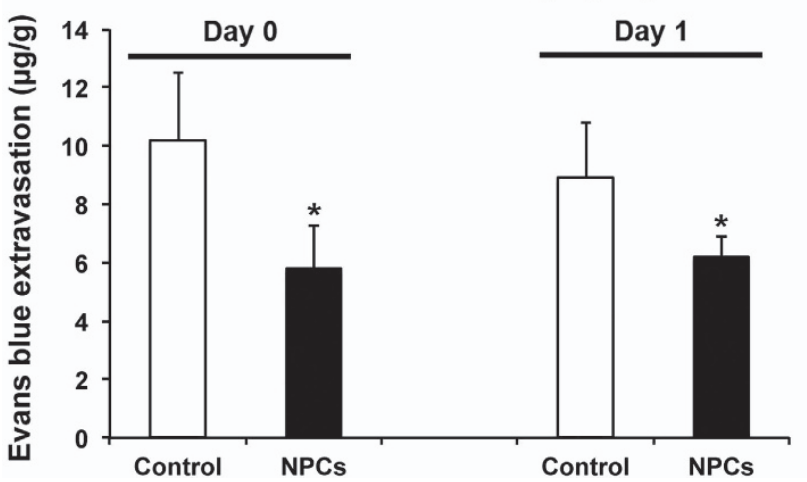

d

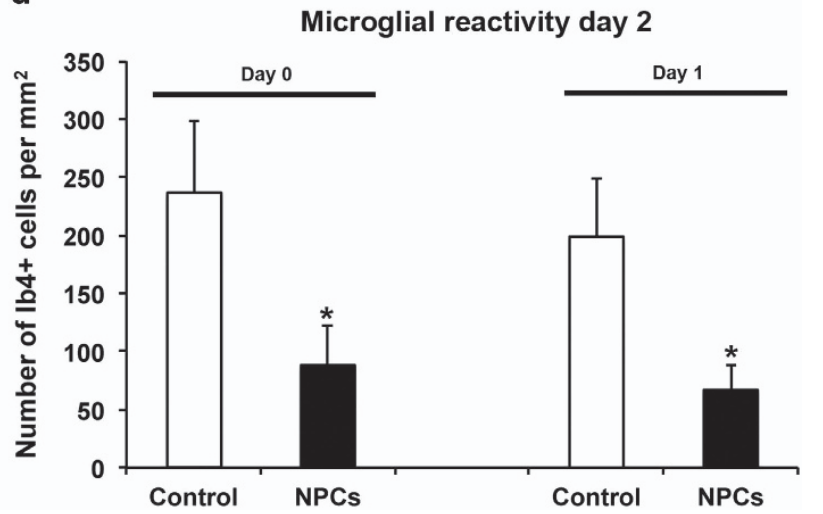

Figure 5 Acute transplantation of neural progenitor cells (NPCs) induces neuroprotection via stabilization of blood-brain barrier (BBB) and reduction in post-ischemic inflammation. Mice received intravenous injections of either PBS (control) or NPCs on day 0 or on day 1 post stroke. Brain injury was assessed using TTC staining (a) and TUNEL staining (b) on day 2 after induction of stroke. Stability of the BBB (c) was analyzed measuring extravasation of Evans blue photometrically, which was injected 2 hours before killing of animals. (d) Microglial activation on day 2 post stroke was immunohistochemically analyzed within defined regions of interest as described in the Materials and Methods. All data are given as mean \pm S.D. *Significantly different from controls, $P<0.05$. Scale bars: $50 \mu \mathrm{m}$

is supposed to be reduced. ${ }^{3}$ In this sense, sustained neuroprotection and long-term functional recovery after acute NPC transplantation rather is a consequence of initial neuroprotection than stimulation of post-ischemic endogenous angioneurogenesis; the latter was not affected when NPCs were transplanted at acute time points. Mechanisms underlying post-ischemic neuroprotection after acute stem cell transplantation imply a variety of different events, among which stabilization of the BBB and reduction in post-ischemic inflammatory responses are most critically involved. ${ }^{4,7,11}$
As such, modulation of both central and peripheral inflammatory responses as observed in the present study might be one key factor for neuroprotection after acute cell delivery. Yet, the precise interplay between post-ischemic inflammation and NPCs is still elusive and most likely multimodal. Inflammatory responses must not necessarily be detrimental but can also help mediate NPC-induced neuroprotection via indirect mechanisms including homing signals for NPCs. ${ }^{32}$ However, elucidating these mechanisms was not the scope of the present work. 
a

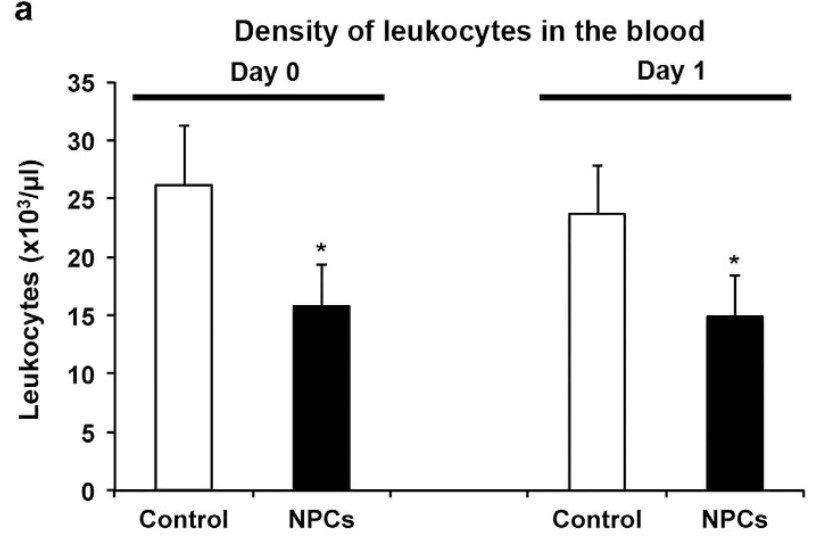

b

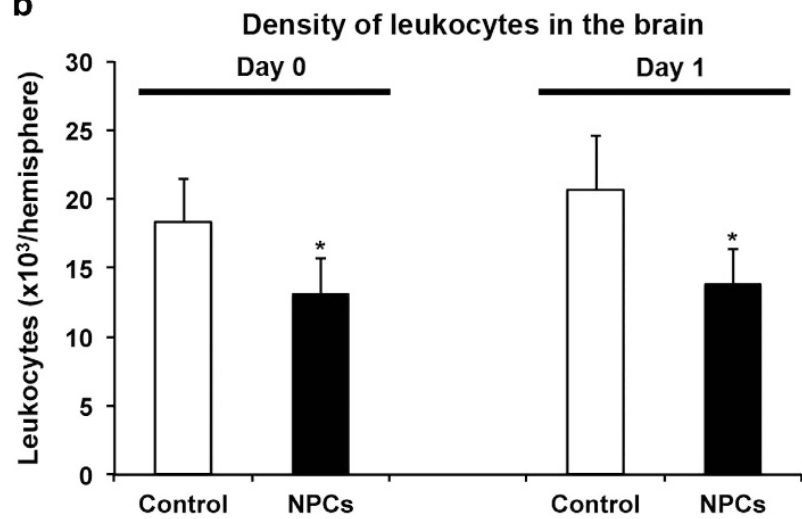

Figure 6 Acute delivery of neural progenitor cells (NPCs) modulates peripheral and central immune response. Mice were treated with PBS (control) or NPCs on day 0 or on day 1 , respectively. Absolute amounts of $C D 45^{+}$leukocytes were measured within the blood (a) and the ischemic hemisphere of the brain (b) on day 2 after induction of stroke. All data are given as mean \pm S.D. *Significantly different from controls, $P<0.05$

Although post-acute transplantation of NPCs did not result in reduced brain injury, functional recovery was enhanced in mice that had received NPCs 4 weeks post stroke as compared with the corresponding controls. In this context, stem cells or progenitor cells are known to induce neuroregeneration via paracrine effects, ${ }^{2,11,33}$ albeit without having significant neuronal differentiation capabilities themselves, as has been shown for MSCs. ${ }^{34}$ By-stander effects due to grafted cells are thought to be mediated via soluble factors, thus changing the extracellular milieu and contributing to endogenous neuroregeneration as well as neuroplasticity. $3,16,33,35$ The latter has recently been recognized as one means of neuroregeneration after stroke, involving both ipsilateral and especially contralateral axonal remodeling. ${ }^{36,37}$ However, neuroplasticity requires a critically increased number of NPCs within the lesion site as exemplarily described for intracerebral cell grafting, ${ }^{4,24}$ thus guaranteeing sufficient concentrations of soluble cell mediators within the ischemic brain. This is the case when NPCs are grafted at chronic stages of the disease where the extracellular milieu is more favorable than during acute pro-inflammatory stages of stroke.

Nevertheless, one must not neglect a possible interplay between grafted NPCs on the one hand and endogenous cells such as SVZ-derived NPCs on the other hand. As mentioned afore, paracrine effects due to grafted cells after post-acute transplantation of NPCs induced enhanced post-ischemic angioneurogenesis 3 months after induction of stroke. Consequently, increased numbers of endogenous SVZderived NPCs, which are not integrated within the residing neural network and similar in nature to grafted NPCs, could also act as 'mini-pumps', thus constantly secreting trophic factors and contributing to functional recovery as well. However, to which extent endogenous NPCs contribute to increased functional recovery after post-acute NPC transplantation remains elusive, making additional experiments such as the use of transgenic mice with ablation of endogenous SVZ-derived NPCs necessary. This, however, was beyond the scope of the current work.

Noteworthy, the present study is the first one showing that single intravenous transplantation of NPCs induces neuroregeneration even when given as late as 4 weeks after stroke onset. Successful cell transplantation at chronic stages of the disease thus implies great clinical impact, providing a broad therapeutic time window. Once having overcome safety issues and dose-response relations that are currently under investigation in clinical trials, ${ }^{38}$ future clinical trials might focus on combinational therapeutic approaches using both acute rtPA-mediated thrombolysis and late intravenous cell transplantation.

In conclusion, acute NPC delivery results in sustained neuroprotection via stabilization of the BBB and modulation of post-ischemic immune responses, whereas late post-acute NPC delivery enhances post-ischemic angioneurogenesis and axonal plasticity. Post-ischemic functional recovery, however, is independent of NPC delivery timing. Thus, NPC transplantation offers an interesting tool with a broad therapeutic time window in addition to existing recanalizing thrombolytic strategies, which might set the path for new treatment paradigms in the future.

\section{Materials and Methods}

Animal numbers, surgical procedures and cell transplantation. All animal procedures were in accordance with the National European Institutes of Health guidelines for the care and use of laboratory animals and approved by local authorities. Animals had free access to food and water. All treatment paradigms and statistical analyses were blinded to experimenters and analysts. Male C57BL6/J mice (10-12 weeks, 23-25 g; Harlan, Rossdorf, Germany) were used for in vivo experiments. Mice were subjected to middle cerebral artery occlusion (MCAO) for 30 min under $1 \%$ isoflurane plus $69 \% \mathrm{~N}_{2} \mathrm{O}$ and $30 \% \mathrm{O}_{2}$ anesthesia as previously described. ${ }^{39}$ Briefly, cerebral ischemia was induced by transient occlusion of the left MCAO using a silicon-coated filament $(180 \mu \mathrm{m}$ diameter; Doccol, Sharon, MA, USA). Regional cerebral blood flow was constantly recorded via Laser Doppler flow measurement.

For transplantation of NPCs, a total of $10^{6}$ cells in $200 \mu$ l of PBS was intravenously administered during reperfusion (day 0). Alternatively, cells were injected on day 1 or on day 28 post stroke. A volume of $200 \mu$ of PBS was injected into control animals at the time points given. For some experiments, $5 \times 10^{6}$ or $10^{7}$ NPCs were injected. For assessment of optimal cell numbers (Figure 1), nine animals were used per condition. Within the animal group that was given $10^{7} \mathrm{NPCs}$, three animals died and were therefore excluded from the study $(n=6$ used for statistical analysis in this group). Survival rate for the remaining groups was $100 \%$. Number of mice used for long-term statistical analysis (i.e., for up to 84 days post stroke) was $12-13$ per experimental condition with survival rates ranging from 80 to $100 \%$. For short-term survival (Figure 5), six mice per condition were used (except for Evans blue measurement, $n=4$ per condition) with survival rates of $100 \%$ for each condition. Applying ELISA tests for detection of selected growth factors within the ischemic hemisphere, an $n=6$ was used with no loss of animals. 
To detect newborn endogenous cells within the brain, mice surviving for 84 days received single daily intraperitoneal injections of bromodeoxyuridine (BrdU; $50 \mathrm{mg} / \mathrm{kg}$ body weight) from days 8 to 40 post stroke. To study whether application of NPCs affects axonal length and axonal sprouting, the anterograde tract tracer biotinylated dextran amine (BDA, Molecular Probes, Eugene, OR, USA) was stereotactically applied into the contralateral cortex 70 days after induction of stroke for labeling of axons and terminals as previously described. ${ }^{23}$ For these experiments, the same animals were used as for immunohistochemical long-term analysis mentioned above (i.e., $n=12-13$ per condition). Mice were deeply anesthetized and fixed into a stereotactic frame. BDA solution $(2 \mu$; $10 \%$ solution

a
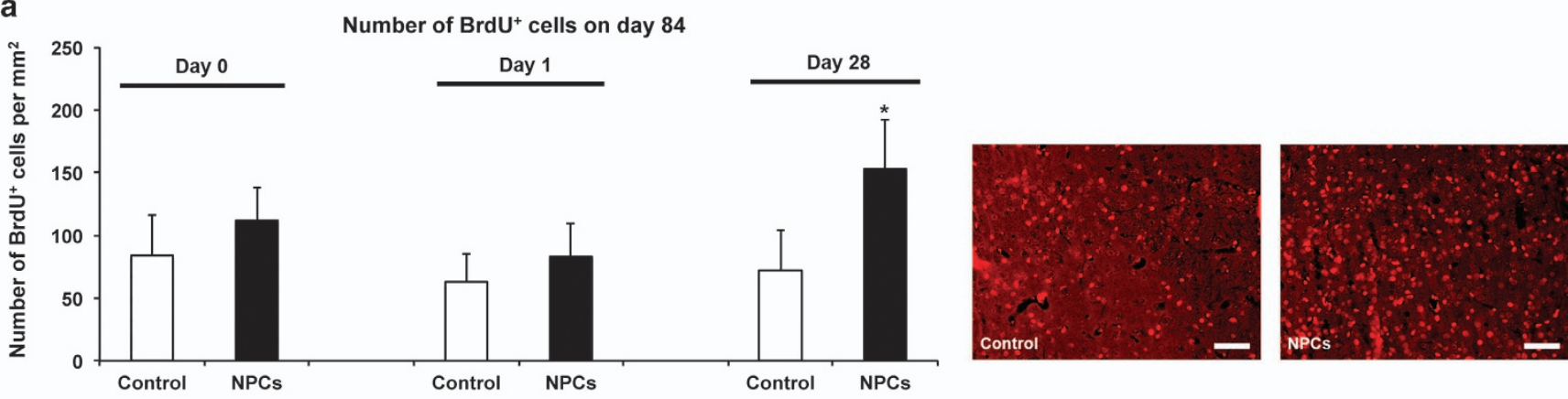

b Differentiation analysis of $\mathrm{BrdU}^{+}$cells on day 84
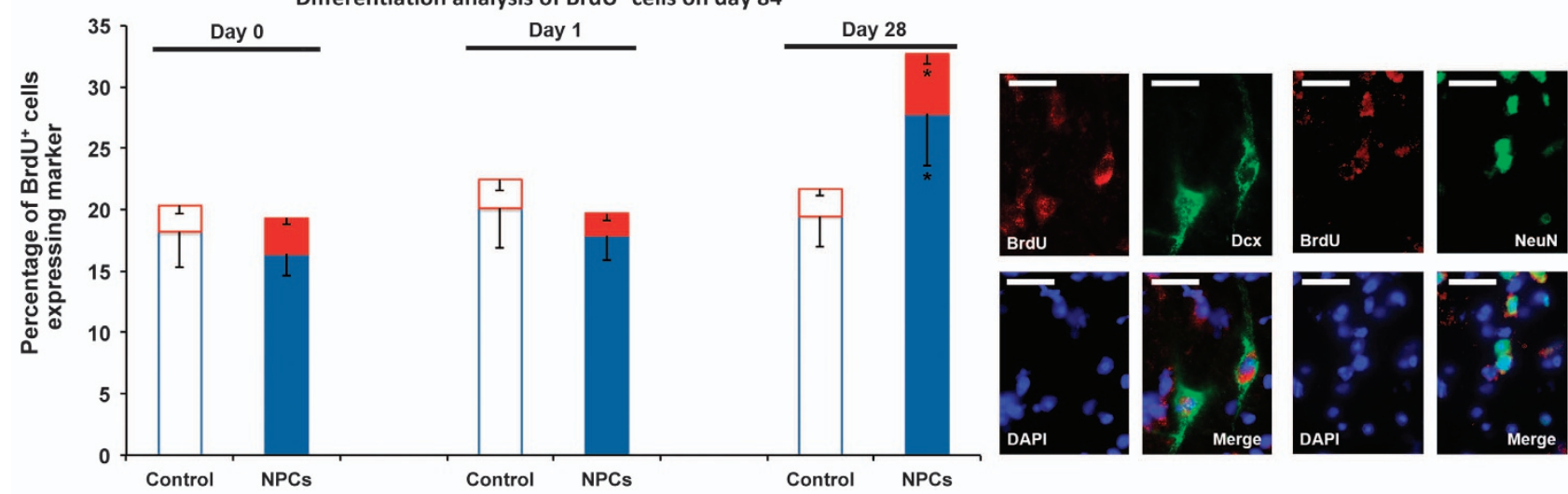

C

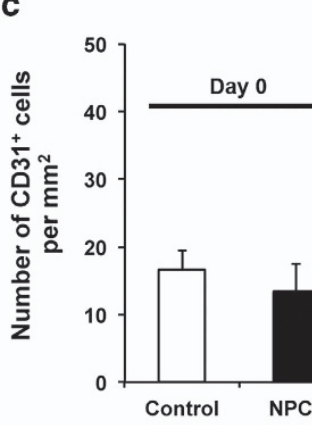

Number of CD31+ cells on day 84
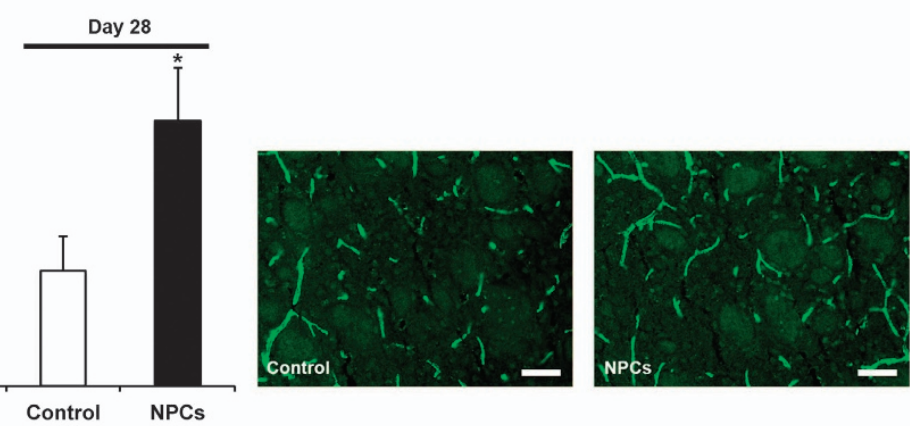

d
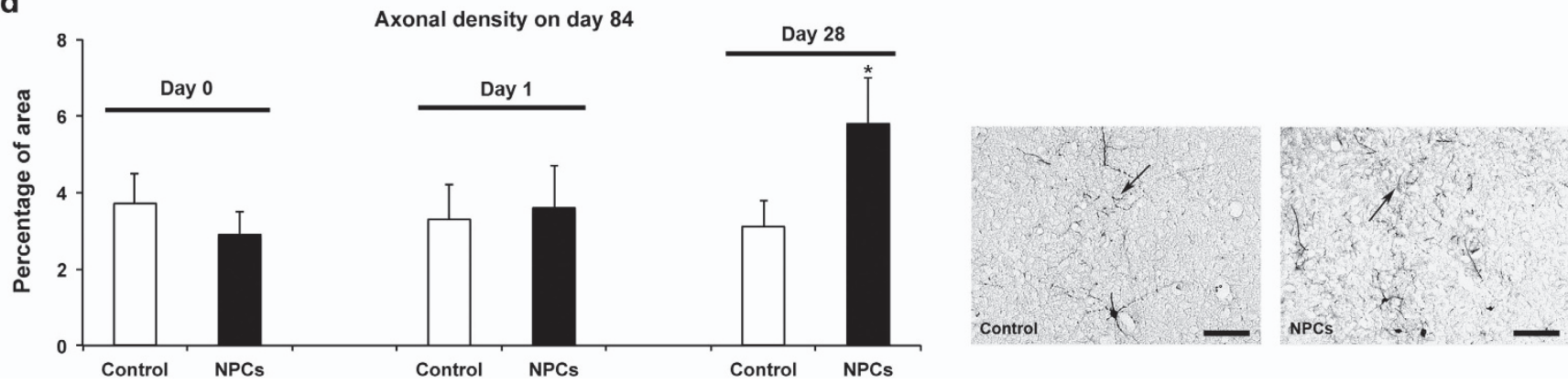
dissolved in $0.1 \mathrm{mM}$ PBS) was injected at $0.5 \mathrm{~mm}$ rostral to bregma, $2.5 \mathrm{~mm}$ lateral to the midline, and $1.5 \mathrm{~mm}$ deep from the cortical surface over $5 \mathrm{~min}$. Thereafter, the needle was kept in situ for an additional 5 min before removal.

Cell culture. NPCs were isolated from the SVZ of adult mice expressing enhanced green fluorescent protein (eGFP; 6-8 weeks of age), and cultured as neurospheres in DMEM-F12 + Glutamax (Gibco, Darmstadt, Germany) supplemented with $2 \mu \mathrm{g} / \mathrm{ml}$ epidermal growth factor (EGF) and $2 \mu \mathrm{g} / \mathrm{ml}$ human basic fibroblast growth factor (bFGF; Invitrogen, Frankfurt, Germany) as previously described. ${ }^{22}$ Cells were passaged every 6-9 days. For transplantation, cells from passages 3-8 were dissociated to a single cell suspension by incubation with Accutase (Sigma, Taufkirchen, Germany) at $37^{\circ} \mathrm{C}$ for $10-15 \mathrm{~min}$, followed by gentle trituration.

Behavioral testing. To study effects of intravenous transplantation of SVZderived NPCs on post-stroke motor coordination, we tested the animals on the rota rod, the tight rope and the corner turn test. All animals were trained 1 day before MCAO surgery to assure similar interindividual test performance followed by testing on days $35,42,56$ and 84 after ischemia. The rota rod test, the tight rope test and the corner turn test were performed as previously described. ${ }^{4,40}$ Briefly, for the rota rod test, mice were placed on the rotating drum with an accelerating speed of $4-40 \times g$ (Ugo Basile, Torino, Italy). After $260 \mathrm{~s}$, the maximum speed was achieved. Each animal was tested for a maximum of $300 \mathrm{~s}$ or until the animal dropped, and the time was recorded. For the tight rope test, animals were placed on a $60-\mathrm{cm}$ long tight rope and allowed to grasp it with their forepaws. Healthy animals grasped the rope with four paws and tail followed by moving to reach the platform on either side, whereas mice having stroke-induced motor deficits could not lift their hind paws and fail to reach the end of the rope or eventually fall off onto the soft clothing placed underneath. All animals were tested twice per time point. Maximum test time was $60 \mathrm{~s}$. Outcomes were scored from 0 ( $\min )$ to 20 (max) according to a validated score described earlier depending on the time spent on the rope and whether the animals could reach the platform. ${ }^{40}$ For the corner turn test, two vertical boards were attached to each other at an angle of $30^{\circ}$, and the mouse was placed in between. Whereas a healthy mouse had no side preference while turning from the corner, a mouse with stroke preferentially turn to the left, non-impaired body side. ${ }^{41}$ Each animal was tested 10 times per session and the laterality index was calculated according to the following formula: (number of left turns - number of right turns) $/ 10$.
Assessment of post-stroke cognitive impairment was performed using the water maze test as described previously. ${ }^{22}$ Briefly, mice were placed into a swimming pool that was filled to a depth of $15 \mathrm{~cm}$ with water kept at room temperature (RT). A transparent platform was submerged with the top located $1 \mathrm{~cm}$ below the surface. Data shown for each time point are means out of eight runs, with four runs performed in the morning and four runs performed in the afternoon of the corresponding test day. The platform was always located in the center of the same quadrant and animals were always put into the same of one of the remaining quadrants. If animals did not reach the platform after $90 \mathrm{~s}$, then they were guided to the platform and allowed to stay there for $30 \mathrm{~s}$. Both swimming velocity and time needed to reach the platform were statistically analyzed using a computer-based system (TSE Systems, Bad Homburg vor der Höhe, Germany).

Tissue processing and immunostaining. At the time points given, mice were euthanized with $7 \%$ chloralhydrate by means of i.p. injections $(300 \mu \mathrm{l} /$ animal) and transcardially perfused with saline followed by $4 \%$ paraformaldehyde. The brains were removed, incubated with gradually increasing concentrations of sucrose $(5-30 \%)$ over 3 days and then preserved at $-80^{\circ} \mathrm{C}$. Coronal cryostat sections $(20 \mu \mathrm{m}$ thick) were prepared and used for immunohistochemical stainings.

Quantitative analyses for the immunostained brain sections were performed by defining regions of interest (ROIs) within the ischemic striatum as described earlier. ${ }^{4}$ Stereotaxic coordinates were AP $=+0.14 \mathrm{~mm}, \mathrm{ML}= \pm 1.5-2.25 \mathrm{~mm}$ and $\mathrm{DV}=$ $-2.5-3.25 \mathrm{~mm}$. Three sections per animal and ROI were used per condition. The following primary antibodies were used: monoclonal mouse anti-BrdU antibody (1:400; Roche, Basel, Switzerland), monoclonal rat anti-BrdU antibody (1:400; Abcam, Cambridge, UK), polyclonal rabbit anti-GFP antibody (1:2500; Abcam; used for intensification of the GFP signal due to quenching effects after tissue processing), goat polyclonal anti-doublecortin (1:50; Santa Cruz Biotechnology, Heidelberg, Germany), rat polyclonal anti-GFAP antibody (1:500; Zymed, Paisley, UK), mouse monoclonal anti-CNPase ( 1 : 400; Millipore, Nottingham, UK), a mouse monoclonal anti-NeuN (1:1000; Millipore), a rat biotin-conjugated anti-IB ${ }_{4}$ antibody (1:100; Vector Labs, Peterbourough, UK), or mouse monoclonal anti-nestin (1:500; Millipore). All antibodies were incubated for $18 \mathrm{~h}$ at $4^{\circ} \mathrm{C}$. After repeated washing steps, sections were incubated with secondary antibodies for $1 \mathrm{~h}$ at RT. These were as follows: goat anti-mouse Cy-3 (1:400; Dianova, Hamburg, Germany), goat anti-rat Alexa 594 (1:400; Dianova), goat anti-rat Alexa 488 (1:250; Invitrogen), donkey anti-goat Alexa 488 (1:250; Invitrogen), goat anti-mouse Alexa 488 (1:100; Jackson ImmunoResearch, Suffolk, UK), goat

Table 1 Growth factor concentration on day 84 after induction of stroke

\begin{tabular}{|c|c|c|c|c|c|c|}
\hline & BDNF & EGF & FGF & GDNF & NGF & VEGF \\
\hline Control (day 0) & $39.2 \pm 12.9$ & $12.1 \pm 3.9$ & $35.8 \pm 14.2$ & $172.5 \pm 49.2$ & $229.4 \pm 21.6$ & $129.2 \pm 26.1$ \\
\hline NPCs (day 0) & $28.7 \pm 18.5$ & $9.7 \pm 5.5$ & $40.2 \pm 9.2$ & $148.2 \pm 42.2$ & $191.8 \pm 36.4$ & $149.6 \pm 35.7$ \\
\hline Control (day 1) & $34.7 \pm 10.1$ & $9.9 \pm 3.6$ & $29.7 \pm 18.6$ & $138.9 \pm 54.7$ & $207.4 \pm 41.8$ & $162.9 \pm 40.6$ \\
\hline NPCs (day 1 ) & $36.9 \pm 7.2$ & $13.5 \pm 4.2$ & $37.9 \pm 14.4$ & $182.5 \pm 58.6$ & $201.3 \pm 52.9$ & $181.8 \pm 47.2$ \\
\hline Control (day 28) & $40.8 \pm 16.9$ & $14.9 \pm 7.1$ & $43.8 \pm 22.1$ & $168.3 \pm 46.1$ & $182.1 \pm 31.8$ & $173.7 \pm 38.1$ \\
\hline NPCs (day 28) & $103.4 \pm 32.3^{\mathrm{a}}$ & $13.1 \pm 3.8$ & $38.7 \pm 18.2$ & $259.2 \pm 39.8^{a}$ & $176.4 \pm 29.5$ & $293.5 \pm 50.7^{a}$ \\
\hline
\end{tabular}

Abbreviations: BDNF, brain-derived neurotrophic factor; EGF, epidermal growth factor; FGF, fibroblast growth factor; GDNF, glial cell line-derived neurotrophic factor; NGF, nerve growth factor; NPCs, neural precursor cells; VEGF, vascular endothelial growth factor

Determination of selected growth factors (BNDF, EGF, FGF, GDNF, NGF and VEGF) on day 84 post stroke in brain homogenates from left ischemic hemispheres by means of ELISA. Animals received intravenous injections of either PBS (Control) or neural progenitor cells (NPCs). Days given in brackets refer to the time point of intravenous injection after stroke, where 'day 0 ' implies injection during beginning of reperfusion. All data are given as mean \pm S.D. in $\mathrm{pg} / \mathrm{ml} \mathrm{protein}$

${ }^{a}$ Significantly different from the corresponding control, $P<0.05$

Figure 7 Post-acute transplantation of neural progenitor cells (NPCs) induces increased post-ischemic angioneurogenesis and stimulation of neuroplasticity. All mice received intravenous transplantation of NPCs at the time points given followed by killing of animals on day 84 post stroke. Control animals received PBS only. (a) Analysis of endogenous new-born GFP ${ }^{-}$cells was performed within the ischemic hemisphere using bromodeoxyuridine (BrdU) labeling. Photographs depicted show representative arrangement of BrdU ${ }^{+}$cells within the lesion site taken from mice that were treated with PBS or NPCs on day 28 post stroke. (b) Neuronal differentiation analysis of endogenous $\mathrm{GFP}^{-} \mathrm{BrdU}^{+}$cells regarding co-expression of doublecortin (blue columns) and NeuN (red columns) within ischemic hemispheres. Representative photographs of co-localization between BrdU and Dcx/NeuN were taken from mice treated with NPCs on day 28. (c) Assessment of vascular density was performed within ischemic hemispheres after treatment of mice as described above using CD31 staining. Photographs depicted show representative stainings of mice that were treated with either PBS or NPCs on day 28 post stroke. (d) Axonal density as one means indicating post-ischemic neuroplasticity was measured via stereotactic injection of the anterograde tract tracer biotinylated dextran amine (BDA) into the contralateral cortex 70 days after stroke. Axon labeling was performed within the ipsilateral hemisphere using 3,3'-diaminobenzidine (DAB) staining on day 84 post stroke. Axonal densities within the cortex of the ischemic hemisphere were measured from six fields per section out of eight sections of each mouse divided by total mean densities of all mice. Results are given as percentage of proportional areas. Representative photographs were taken from mice that were treated with either PBS or NPCs. All data are given as mean \pm S.D. ${ }^{*}$ Significantly different from controls, $P<0.05$. Scale bars: $50 \mu \mathrm{m}(\mathbf{a}, \mathbf{c}$ and $\mathbf{d})$ and $20 \mu \mathrm{M}(\mathbf{b})$ 
anti-mouse Alexa 488 (1: 400; Invitrogen), goat anti-mouse Cy-3 (1: 100; Jackson ImmunoResearch), goat anti-rat Cy-3 antibody (1:200, Abcam), donkey anti-goat Cy-3 secondary antibody (1:500; Dianova).

Terminal deoxynucleotidyl transferase (TdT)-mediated dUTP nick end labeling (TUNEL) was performed on day 2 after induction of stroke. Sections were incubated with proteinase $\mathrm{K}\left(7 \mathrm{~min}\right.$ at $\left.37^{\circ} \mathrm{C}\right)$ followed by exposure to the TdT enzyme reaction following the manufacturer's manual (Roche). Thereafter, sections were stained with a streptavidin-Alexa-488-conjugated secondary antibody ( $2 \mathrm{~h}$ at RT; Invitrogen) and analyzed.

To quantify $\mathrm{BDA}^{+}$fibers, sections were incubated overnight with an avidinbiotin-peroxidase complex (ABC Elite; Vector Laboratories, Lörrach, Germany). Stainings were revealed with 3,3'-diaminobenzidine (DAB) containing $0.4 \%$ ammonium sulfate and $0.004 \% \mathrm{H}_{2} \mathrm{O}_{2}$. Analysis was performed by means of measurement of $\mathrm{BDA}^{+}$axonal densities within the cortex of the ischemic hemisphere (six fields per section) from eight sections of each mouse divided by total mean densities of all mice as described elsewhere. ${ }^{23}$ Results are given as percentage of proportional areas.

Infarct volume analysis. Assessment of infarct volumes was performed using either cresyl violet staining (Figure 1) or 2,3,5-triphenyltetra-zolium chloride (TTC; Figure 5) staining. For the former, cryostat sections of $20 \mu \mathrm{m}$ thickness were cut every $400 \mu \mathrm{m}$ between $+1 \mathrm{~mm}$ and $-3 \mathrm{~mm}$ from bregma. ${ }^{42}$ For the latter, brains were removed and cut into four slices of $2 \mathrm{~mm}$ each followed by staining with TTC. Stained sections/slices were scanned followed by a computer-based analysis of infarct volumes using the Image $\mathrm{J}$ software (http://imagej.nih.gov/ij/ index.html) by subtracting the area of the non-lesioned ipsilateral hemisphere from that of the contralateral side. Infarct volume sizes were calculated by integration of the lesioned areas.

Flow cytometry analysis. Flow cytometry was used for post-stroke detection of absolute amounts of leukocytes (CD45 ${ }^{+}$high $)$within the blood and the brain as described by Chu et al..$^{43}$ with slight modifications. Two days after induction of stroke, mice were killed and blood samples were taken (cardiac puncture) followed by transcardial perfusion with PBS and removal of the brain. For analysis of blood samples, leukocytes were purified using lysis buffer consisting of $155 \mathrm{mM} \mathrm{NH}_{4} \mathrm{Cl}, 10 \mathrm{mM} \mathrm{KHCO}_{3}$ and $3 \mathrm{mM}$ EDTA. For flow cytometry measurements of brain tissue samples, ischemic left hemispheres were mechanically homogenized in a buffer of collagenase type XI $(125 \mathrm{U} / \mathrm{ml})$, hyaluronidase $(60 \mathrm{U} / \mathrm{ml})$ and collagenase $(450 \mathrm{U} / \mathrm{ml})$ in $\mathrm{Ca}^{2+} / \mathrm{Mg}^{2+}$-supplemented PBS (Sigma). Samples were incubated for $20 \mathrm{~min}$ at $37^{\circ} \mathrm{C}$ under constant and gentle agitation. Single cell suspensions were achieved after usage of $70 \mu \mathrm{m}$ nylon cell strainers, washing with PBS and centrifugation (1200 r.p.m. for $12 \mathrm{~min}$ ) followed by resuspension of cell pellets in 30\% percoll (GE Healthcare, Uppsala, Sweden) that included $70 \%$ percoll below and centrifugation of samples for $20 \mathrm{~min}$ at 2400 r.p.m. at RT. Cells were collected and washed in PBS containing 1\% bovine serum albumin. Thereafter, cells were incubated with a rat anti-CD45 (BioLegend, Fell, Germany) antibody for $30 \mathrm{~min}$ at $4^{\circ} \mathrm{C}$. Countbright counting beads (Invitrogen, Carlsbad, CA, USA) were included for assessment of absolute cell numbers. Cells were analyzed using an LSR II (BD Biosciences, Heidelberg, Germany) and FACS Diva software (BD Biosciences).

Measurement of BBB permeability. Animals were given $2 \%$ of Evans blue dye ( $2 \mathrm{ml} / \mathrm{kg}$ body weight) via tail vein cannulation at $46 \mathrm{~h}$ post stroke using a previously described protocol. ${ }^{44}$ Two hours later, mice were killed and transcardiacally perfused with PBS. Thereafter, brains were removed and separated into hemispheres. Left hemispheres were weighed, homogenized in $2 \mathrm{ml}$ of $50 \%$ trichloroacetic acid, centrifuged and used for photometric detection of extravasated Evans blue. Fluorescence signal was measured with a luminescence spectrophotometer (excitation at $620 \mathrm{~nm}$, emission at $680 \mathrm{~nm}$ ). An external standard $(62.5-500 \mathrm{ng} / \mathrm{ml})$ was used for calibration. Evans blue dye contents are given as $(\mu \mathrm{g})$ Evans blue dye per $(\mathrm{g})$ tissue.

ELISAs for determination of growth factors. ELISA experiments were performed using samples as described before. ${ }^{4}$ Briefly, left ischemic hemispheres were obtained on day 84 post stroke and complemented with lysis buffer $(50 \mathrm{mM}$ Tris-HCl (pH 7.6), $150 \mathrm{mM} \mathrm{NaCl}, 5 \mathrm{mM} \mathrm{CaCl}_{2}, 0.05 \%$ BRIJ-35, $0.02 \% \mathrm{NaN}_{3}$ and $1 \%$ Triton $\mathrm{X}-100$ ) for generation of brain homogenates. Homogenates were centrifuged at $4^{\circ} \mathrm{C}$ at $12000 \times g$ for $5 \mathrm{~min}$. Supernatants were used for detection of the growth factors vascular endothelial growth factor (VEGF; R\&D Systems,
Minneapolis, MN, USA), nerve growth factor (NGF; Promega, Mannheim, Germany), brain-derived neurotrophic factor (BDNF; Promega), glial cell line-derived neurotrophic factor (GDNF; Promega), FGF (R\&D Systems) and EGF (R\&D Systems) by means of commercial mouse ELISA kits according to the manufacturer's instructions.

Statistical analysis. All data are given as mean \pm S.D. For comparison between two groups, the Student's $t$-test was used. Comparison between multiple groups was done via a one-way analysis of variance (ANOVA) followed by the Tukey's post hoc test. A $P$-value of $<0.05$ was considered as statistically significant.

\section{Conflict of Interest}

The authors declare no conflict of interest.

1. Leong WK, Henshall TL, Arthur A, Kremer KL, Lewis MD, Helps SC et al. Human adult dental pulp stem cells enhance poststroke functional recovery through non-neural replacement mechanisms. Stem Cells Transl Med 2012; 1: 177-187.

2. Bacigaluppi M, Pluchino S, Martino G, Kilic E, Hermann DM. Neural stem/precursor cells for the treatment of ischemic stroke. J Neurol Sci 2008; 265: 73-77.

3. Bliss TM, Andres RH, Steinberg GK. Optimizing the success of cell transplantation therapy for stroke. Neurobiol Dis 2010; 37: 275-283.

4. Doeppner TR, Ewert TA, Tonges L, Herz J, Zechariah A, Elali A et al. Transduction of neural precursor cells with TAT-heat shock protein 70 chaperone: therapeutic potential against ischemic stroke after intrastriatal and systemic transplantation. Stem cells 2012; 30: $1297-1310$.

5. Zheng W, Honmou O, Miyata K, Harada K, Suzuki J, Liu H et al. Therapeutic benefits of human mesenchymal stem cells derived from bone marrow after global cerebral ischemia. Brain Res 2010; 1310: 8-16.

6. Banerjee S, Williamson DA, Habib N, Chataway J. The potential benefit of stem cell therapy after stroke: an update. Vasc Health Risk Manag 2012; 8: 569-580.

7. Schwarting S, Litwak S, Hao W, Bahr M, Weise J, Neumann H. Hematopoietic stem cells reduce postischemic inflammation and ameliorate ischemic brain injury. Stroke 2008; 39: 2867-2875.

8. Blum B, Benvenisty N. The tumorigenicity of human embryonic stem cells. Adv Cancer Res 2008; 100: 133-158.

9. Blum B, Benvenisty N. The tumorigenicity of diploid and aneuploid human pluripotent stem cells. Cell Cycle 2009; 8: 3822-3830.

10. Bonnamain V, Neveu I, Naveilhan P. Neural stem/progenitor cells as a promising candidate for regenerative therapy of the central nervous system. Front Cell Neurosci 2012; 6: 17.

11. Bacigaluppi M, Pluchino S, Peruzzotti Jametti L, Kilic E, Kilic U, Salani G et al. Delayed post-ischaemic neuroprotection following systemic neural stem cell transplantation involves multiple mechanisms. Brain 2009; 132(Pt 8): 2239-2251.

12. Darsalia V, Allison SJ, Cusulin C, Monni E, Kuzdas D, Kallur T et al. Cell number and timing of transplantation determine survival of human neural stem cell grafts in stroke-damaged rat brain. J Cereb Blood Flow Metab 2011; 31: 235-242.

13. Minnerup J, Kim JB, Schmidt A, Diederich K, Bauer H, Schilling $M$ et al. Effects of neural progenitor cells on sensorimotor recovery and endogenous repair mechanisms after photothrombotic stroke. Stroke 2011; 42: 1757-1763.

14. Giusto $E$, Donega $M$, Cossetti $C$, Pluchino S. Neuro-immune interactions of neural stem cell transplants: from animal disease models to human trials. Exp Neurol 2013; e-pub ahead of print 16 March 2013; doi:10.1016/j.expneurol.2013.03.009.

15. Dibajnia $\mathrm{P}$, Morshead CM. Role of neural precursor cells in promoting repair following stroke. Acta Pharmacol Sin 2013; 34: 78-90.

16. Hicks A, Jolkkonen J. Challenges and possibilities of intravascular cell therapy in stroke. Acta Neurobiol Exp 2009; 69: 1-11.

17. Guzman R, Choi R, Gera A, De Los Angeles A, Andres RH, Steinberg GK. Intravascular cell replacement therapy for stroke. Neurosurg Focus 2008; 24: E15.

18. Shen CC, Lin CH, Yang YC, Chiao MT, Cheng WY, Ko JL. Intravenous implanted neural stem cells migrate to injury site, reduce infarct volume, and improve behavior after cerebral ischemia. Curr Neurovasc Res 2010; 7: 167-179.

19. Janowski M, Walczak P, Date I. Intravenous route of cell delivery for treatment of neurological disorders: a meta-analysis of preclinical results. Stem Cells Dev 2010; 19 : $5-16$.

20. Doeppner TR, Hermann DM. Mesenchymal stem cells in the treatment of ischemic stroke: progress and possibilities. Stem Cells Cloning 2010; 3: 157-163.

21. Scheibe F, Ladhoff J, Huck J, Grohmann M, Blazej K, Oersal A et al. Immune effects of mesenchymal stromal cells in experimental stroke. J Cereb Blood Flow Metab 2012; 32: 1578-1588.

22. Doeppner TR, El Aanbouri M, Dietz GP, Weise J, Schwarting S, Bahr M. Transplantation of TAT-Bcl-xL-transduced neural precursor cells: long-term neuroprotection after stroke. Neurobiol Dis 2010; 40: 265-276.

23. Yan T, Chopp M, Ye X, Liu Z, Zacharek A, Cui $Y$ et al. Niaspan increases axonal remodeling after stroke in type 1 diabetes rats. Neurobiol Dis 2012; 46: 157-164. 
24. Stroemer P, Patel S, Hope A, Oliveira C, Pollock K, Sinden J. The neural stem cell line $\mathrm{CTX} 0 \mathrm{E} 03$ promotes behavioral recovery and endogenous neurogenesis after experimental stroke in a dose-dependent fashion. Neurorehabil Neural Repair 2009; 23: 895-909.

25. Shen LH, Li Y, Chen J, Zacharek A, Gao Q, Kapke A et al. Therapeutic benefit of bone marrow stromal cells administered 1 month after stroke. J Cereb Blood Flow Metab 2007; 27: 6-13.

26. Rosenblum S, Wang N, Smith TN, Pendharkar AV, Chua JY, Birk H et al. Timing of intraarterial neural stem cell transplantation after hypoxia-ischemia influences cell engraftment, survival, and differentiation. Stroke 2012; 43: 1624-1631.

27. Song M, Kim YJ, Kim YH, Roh J, Kim SU, Yoon BW. Effects of duplicate administration of human neural stem cell after focal cerebral ischemia in the rat. Int $J$ Neurosci 2011; 121 457-461.

28. Moriyama Y, Takagi N, Tanonaka K. Intravenous injection of neural progenitor cells improved depression-like behavior after cerebral ischemia. Transl Psychiatry 2011; 1: e29.

29. Hassani Z, O'Reilly J, Pearse Y, Stroemer P, Tang E, Sinden J et al. Human neura progenitor cell engraftment increases neurogenesis and microglial recruitment in the brain of rats with stroke. PLoS One 2012; 7: e50444.

30. Bliss T, Guzman R, Daadi M, Steinberg GK. Cell transplantation therapy for stroke. Stroke 2007; 38(2 Suppl): 817-826

31. Dirnagl U, ladecola C, Moskowitz MA. Pathobiology of ischaemic stroke: an integrated view. Trends Neurosci 1999; 22: 391-397.

32. Kokaia Z, Martino G, Schwartz M, Lindvall O. Cross-talk between neural stem cells and immune cells: the key to better brain repair? Nat Neurosci 2012; 15: 1078-1087.

33. Martino G, Bacigaluppi M, Peruzzotti-Jametti L. Therapeutic stem cell plasticity orchestrates tissue plasticity. Brain 2011; 134(Pt 6): 1585-1587

34. Uccelli A, Moretta L, Pistoia V. Mesenchymal stem cells in health and disease. Nat Rev Immunol 2008; 8: 726-736

35. Martino G, Pluchino S, Bonfanti L, Schwartz M. Brain regeneration in physiology and pathology: the immune signature driving therapeutic plasticity of neural stem cells. Physiol Rev 2011; 91: 1281-1304.

36. Pekna M, Pekny M, Nilsson M. Modulation of neural plasticity as a basis for stroke rehabilitation. Stroke 2012; 43: 2819-2828.

37. Liu Z, Li Y, Zhang X, Savant-Bhonsale S, Chopp M. Contralesional axonal remodeling of the corticospinal system in adult rats after stroke and bone marrow stromal cell treatment. Stroke 2008; 39: 2571-2577.
38. Kalladka D, Muir KW. Brain repair: cell therapy in stroke. Stem Cells Cloning 2014; 7: $31-44$.

39. Doeppner TR, Mlynarczuk-Bialy I, Kuckelkorn U, Kaltwasser B, Herz J, Hasan MR et al. The novel proteasome inhibitor BSc2118 protects against cerebral ischaemia through HIF1A accumulation and enhanced angioneurogenesis. Brain 2012; 135(Pt 11): 3282-3297.

40. Doeppner TR, Bretschneider E, Doehring M, Segura I, Senturk A, Acker-Palmer A et al. Enhancement of endogenous neurogenesis in ephrin-B3 deficient mice after transient focal cerebral ischemia. Acta Neuropathol 2011; 122: 429-442.

41. Zhang L, Schallert T, Zhang ZG, Jiang Q, Arniego P, Li Q et al. A test for detecting longterm sensorimotor dysfunction in the mouse after focal cerebral ischemia. $J$ Neurosci Methods 2002; 117: 207-214.

42. Herz J, Hagen SI, Bergmuller E, Sabellek P, Gothert JR, Buer J et al. Exacerbation of ischemic brain injury in hypercholesterolemic mice is associated with pronounced changes in peripheral and cerebral immune responses. Neurobiol Dis 2014; 62: 456-468.

43. Chu HX, Kim HA, Lee S, Moore JP, Chan CT, Vinh A et al. Immune cell infiltration in malignant middle cerebral artery infarction: comparison with transient cerebral ischemia. J Cereb Blood Flow Metab 2014; 34: 450-459.

44. Chiba Y, Sasayama T, Miyake S, Koyama J, Kondoh T, Hosoda K et al. Anti-VEGF receptor antagonist (VGA1155) reduces infarction in rat permanent focal brain ischemia. Kobe J Med Sci 2008; 54: E136-E146.

(c) (i) $(\Theta$ Cell Death and Disease is an open-access journal published by Nature Publishing Group. This work is licensed under a Creative Commons Attribution-NonCommercialNoDerivs 3.0 Unported License. The images or other third party material in this article are included in the article's Creative Commons license, unless indicated otherwise in the credit line; if the material is not included under the Creative Commons license, users will need to obtain permission from the license holder to reproduce the material. To view a copy of this license, visit http://creativecommons.org/ licenses/by-nc-nd/3.0/ 